\title{
Comparison Between Neutrophyl Level with Clinical Outcome In Acute Ischemic Stroke < 72 hours and after 7 days onset
}

\author{
Amira Fitriananda ${ }^{a}$, Mohammad Saiful Ardhi ${ }^{\text {b }}$
}

aamirafitriananda@yahoo.com

${ }^{a}$ Resident Student of Department of Neurology, Faculty of Medicine Universitas Airlangga, Surabaya, 60131, Indonesia

${ }^{b}$ Division of Neuro-vascular, Department of Neurology, Faculty of Medicine Universitas Airlangga, Surabaya, 60131, Indonesia

\begin{abstract}
Background and Purpose: The executives patients with ceaseless stroke created to treatment that fast and exact on target can reduce morbidity rate patients with strokes. In intense ischemic stroke, irritation process came about in neutrophil cells preparation as the main leucocytes coming through in the ischemic region. This review meant to correlation between changes in neutrophil levels and clinical result in patients with intense ischemic stroke $<72$ hours and the 7 days beginning at Dr. Soetomo medical clinic. Method: A cross-sectional technique was utilized in this study. Test information were gathered from the stroke library in the neurologic room at Dr. Soetomo medical clinic from January to March 2021. Neutrophil level were gathered upon $<72$ hours and 7 days of beginning. The information were surveyed utilizing National Institutes of Health Stroke Scale (NIHSS) upon release. Information was dissected utilizing SPSS rendition 24 with $\mathrm{p}<0.05$ as huge worth. Result: From the stroke library information, it was observed that 65 subjects have satisfied the measures for this review. In the comparison of neutrophil levels and NIHSS scores on onset $<72$ hours NIHSS scores were found in moderate NIHSS 14 subjects $(21,5 \%)$ with a mean neutrophil of $8.62 \pm 2.5 \times 103 / \mathrm{uL}$ statistically significant with $\mathrm{p}=0.015$, while the after 7 days onset results of increased neutrophils were found in moderate NIHSS 18 subjects $(27,7 \%)$ with a mean neutrophil of $8.03 \pm 3.2 \times 103 / \mathrm{uL}$. The difference results were found to be statistically significant with $p=0.037$. Conclusion: There is a significant difference between changes in neutrophil levels and clinical outcome in patients with acute ischemic stroke $<72$ hours and the onset of day 7, that the higher the neutrophil level, the worse the clinical outcome of stroke
\end{abstract}

Keywords: Neutrophil; Ischemic Stroke; clinical outcome; NIHSS; Mild, moderate and severe deficits.

\section{Introduction}

Stroke is one of the fundamental death and inability around the world. The administration of patients with stroke keeps on developing. Brief and designated treatment can lessen bleakness in patients with stroke. In patients with late or unseemly treatment, it will for the most part lead to mind and treatment that consumes a large chunk of the day so it can create social issues locally.

The cases of stroke in the United States is the third leading cause of death after cancer and heart disease. The 700,000 cases in a year, including 600,000 cases of ischemic stroke and 100,000 bleeding cases.(Ropper et al., 2019) In Asia, the incidence of stroke is between 116-483/100.00 per year In the Indonesian population, the prevalence of stroke reaches $8 / 1000$ population, with a death rate from stroke of around 193.3/100.00 per year.(Venketasubramanian et al., 2017) .

Brain blood flow, $80 \%$ comes from the carotid vascular system originating from the anterior circulation while the rest comes from the posterior circulation originating from the vertebrobasilar system. The incidence of thrombus and thromboembolism in the anterior circulation is more in the distribution of the middle cerebral 
artery, so the area supplied by the middle cerebral artery common cause the most of ischemic stroke.(Sacco et al., 2013).

Patients with stroke having management developed to treatment that fast and precise on target can reduce morbidity rate in patients with strokes. In patients with treatment late or not usually right will cause treatment and the treatment takes a lot of time relatively long so can cause social problems in public.(Campbell and Khatri, 2020).

The inflammatory response in the ischemic stroke process is an important process that affects the course of stroke in the acute phase, because it can aggravate the course of ischemic stroke by accelerating the development of the penumbra into infarction. Inflammatory elements in the form of cellular elements such as neutrophils and molecular elements such as cytokines. During brain ischemia, fundamental events occur in the area around the ischemic cells, including an inflammatory reaction that begins with the production of proinflammatory cytokines in the ischemic area which will lead to the mobilization of leukocytes. The presence of leukocytes, especially neutrophils in ischemic areas, can cause more severe lesions (reperfusion injury) through the plugging mechanism, release of vasoconstrictive mediators, release of hydrolytic enzymes, lipid peroxidase and release of free radicals.(Meloni, 2017).

Damage to brain tissue due to stroke is the cause of clinical deterioration of patients that can end in death or disability. Pathobiological mechanisms that can explain the worsening of the clinical condition of stroke patients are still not well understood. One approach in question is about the role of cytokines in the inflammatory process that occurs during acute ischemic stroke. Cytokines created by $\mathrm{T}$ lymphocytes assume a part in the natural course of tissue harm because of irritation. A few proinflammatory cytokines, for example, IL-1, IL-6, TNF- $\alpha$ are delivered in the beginning phases of the cerebrum ischemic cycle, yet it is as yet indistinct how this provocative interaction can deteriorate the patient's clinical picture.(Eichmann and Thomas, 2013).

In Jickling's study, it was presumed that proinflammatory cytokines, particularly IL-8 assume a part in enrolling neutrophils as a significant part in the provocative reaction in ischemic stroke.(Jickling et al., 2015) Meanwhile, Audebert et al observed that an increment in neutrophils in patients with intense ischemic stroke was related with the seriousness of the stroke and there was a critical connection between the quantity of sore volumes and leukocytes.(Audebert et al., 2004) With the higher the quantity of blood leukocytes, the bigger the volume of the injury. This is on the grounds that initiated leukocytes bring about additional harm to ischemic sores through reperfusion systems or auxiliary injury.(Wang et al., 2015).

Kömürcü in his investigation said that high leukocyte and neutrophil counts were connected with vascular disease and could be a mark of stroke earnestness.(Kömürcü et al., 2020) According to Xu, in his research, that the higher the lesion volume, the higher the number of leukocytes and neutrophils in both ischemic and hemorrhagic strokes, so that a high leukocyte count can be used to predict the size of the lesion volume. (Xu et al., 2019) In the interim, as per Buck HB et al, in his review presumed that fringe leukocytes and high neutrophil counts, barring lymphocyte counts were related with huge infarct volume in intense ischemic stroke.(Buck et al., 2008) In the investigation of Siegler J et al, reasoned that neutrophils in intense ischemic stroke patients with high NIHSS scores at emergency clinic confirmation were related with poor practical outcome.(Walsh et al., 2005) 
In patients with ischemic stroke, there are realized danger factors that can expand mortality and clinical crumbling. The NIHSS assesses neurological clinical outcomes with a wide enough scope, so that it can describe overall brain function and is a rating scale that is currently often used for the assessment of ischemic stroke outcomes. In view of the abovementioned and to the extent the study, research on neutrophil levels with ischemic stroke results has not been completed in Surabaya, so it is important to lead research on the examination between neutrophil levels and intense ischemic stroke results.

\section{Methods}

The methodology used cross sectional study in the research. The goal is to decide the examination between neutrophil level with clinical result in intense ischemic stroke $<72$ hours and following 7 days beginning. The review period was directed from January to March 2021. The essential information was from the Stroke vault. The review populace was intense ischemic stroke patients who got therapy in the Seruni A Room in the Neurology Section of Dr. Soetomo Surabaya. The information gathered included neutrophil esteems at the hour of beginning hospitalized, gender, age, frequency of days in Stroke and NIHSS scores when the patient was released from the clinic $<72$ hours and following 7 days.

The neutrophil level is incorporated as an autonomous variable in this review. The specialists utilized the standard hematology trial of the Clinical Pathology Laboratory of RSUD Dr. Soetomo with ordinary neutrophil level: 2.500-7.500 mm3 or SI: 2.5-7.5 x103/uL, and upper (neutrophil count> 7.5x103/uL). The degree of neutrophils was regularly minded the day of hospitalized with finished blood routine checker.

Clinical results of intense ischemic stroke patients examined were evaluated utilizing The National Institute of Health in Stroke Scale (NIHSS) worksheet. The NIHSS appraisal incorporates: (a) Score <5: gentle neurological deficiency, (b) Score 6-14: moderate neurological shortfall, (c) Score 15-24: serious neurological shortage, (d) Score 25: exceptionally extreme neurological deficit.(Lyden, 2017) The evaluation result remembered for the review was the NIHSS with gentle, moderate, and extreme deficiency ischemic stroke which was the reliant variable.

The accumulated data was using the Statistical Package for the Social Sciences (SPSS) v23 for Windows (IBM Inc., Chicago, IL). The examination was done utilizing an autonomous parametric t-test on the off chance that the aftereffects of the ordinariness test were typically dispersed or non-parametric with the MannWhitney test. The Spearman test was to decide the strength of the relationship with essentially of P-value $<0.05$.

\section{Results}

This study involved 65 subjects which can be seen in (Table 1) shows the distribution of research samples based on age, sex, risk factors, and infection in research subjects. In the male gender group, the most obtained was $61.5 \%$ while the female was $38.5 \%$. In the age group, the largest age group was found at the age of 61-70 years, 20 subjects $(30.5 \%)$ followed by the age of 51-60 years, 16 subjects $(24.6 \%)<45$ years. More risk factors were found in patients with hypertension as many as 49 (75.4\%), and dyslipidemia in $35(53.8 \%)$.

In the comparison of neutrophil levels and NIHSS scores on onset <72 hours (Table 2), the highest NIHSS scores were found in moderate NIHSS 18 subjects $(27,7 \%)$ with a mean of $6.67 \pm 2.5$ x103/Ul while the results of increased neutrophils were found in moderate NIHSS 14 subjects $(21,5 \%)$ with a mean neutrophil of $8.62 \pm$ 
$2.5 \times 103 /$ uL.The distinction results were viewed as measurably critical with $p=0.015$. While the results of the comparison of neutrophil levels and NIHSS onset scores after 7 days of onset (Table 3) showed the highest NIHSS scores were in moderate NIHSS 17 subjects $(26,2 \%)$ with a mean of $6.06 \pm 3.1 \mathrm{x} 103 / \mathrm{uL}$, while the results of increased neutrophils were found in moderate NIHSS. 18 subjects $(27,7 \%)$ with a mean neutrophil of $8.03 \pm 3.2 \times 103 / \mathrm{uL}$. The distinction results were viewed as genuinely critical with $\mathrm{p}=0.037$.

Table 1. Characteristics from the stroke registry

\begin{tabular}{|c|c|c|c|}
\hline \multicolumn{2}{|c|}{ Characteristics } & Total (N:65) (\%) & Mean (Min-Max \pm SD) \\
\hline \multicolumn{4}{|c|}{ Gender } \\
\hline- & women & $25(38.5)$ & \\
\hline & Men & $40(61.5)$ & \\
\hline \multicolumn{2}{|c|}{ Age } & & $57.42(30-83 \pm 12.36)$ \\
\hline \multicolumn{2}{|c|}{$<=40$ years } & $5(7.6)$ & \\
\hline \multicolumn{2}{|c|}{$41-50$ years } & $14(21.5)$ & \\
\hline \multicolumn{2}{|c|}{$51-60$ years } & $16(24.6)$ & \\
\hline \multicolumn{2}{|c|}{$61-70$ years } & $20(30.7)$ & \\
\hline \multicolumn{2}{|c|}{$>70$ years } & $10(15.3)$ & \\
\hline \multicolumn{4}{|c|}{ Risk Factor } \\
\hline \multirow{3}{*}{ - } & Hypertension & $49(75.4)$ & \\
\hline & Dyslipidemia & $35(53.8)$ & \\
\hline & Diabetes mellitus & $20(30.7)$ & \\
\hline \multicolumn{4}{|c|}{ Infection } \\
\hline \multirow{3}{*}{-} & Pneumonia & $8(12.3)$ & \\
\hline & Urinary tract infections & $1(1.5)$ & \\
\hline & Decubitus & $2(3.1)$ & \\
\hline
\end{tabular}

Table 2. Comparison of neutrophil levels and NIHSS scores in patients with acute ischemic stroke onset 72 hours

\begin{tabular}{|c|c|c|c|c|c|c|c|}
\hline \multirow{2}{*}{\multicolumn{2}{|c|}{$\begin{array}{l}\text { Neutrophil level }<72 \mathrm{~N} \\
\text { hours }\end{array}$}} & \multicolumn{3}{|c|}{ NIHSS score $<72$ hours $\mathrm{n}(\%)$} & \multirow{2}{*}{ Average } & \multirow{2}{*}{ SD } & \multirow{2}{*}{ p value* } \\
\hline & & Mild & Moderate & severe & & & \\
\hline Normal 2.5-7.5 x103/uL & 65 & $15(23,1)$ & $18(27,7)$ & $2(3,1)$ & 6.67 & 2.5 & \multirow{2}{*}{$0.015 * *$} \\
\hline Uppers $>7.5$ x103/uL & 65 & $7(10,7)$ & $14(21,5)$ & $9(13,8)$ & 8.62 & 2.4 & \\
\hline
\end{tabular}

*Mann-Whitney U test

**significant

Table 3. Comparison of neutrophil levels and NIHSS scores of patients with acute ischemic stroke and

7 days onset

*Mann-Whitney U test

\begin{tabular}{|c|c|c|c|c|c|c|c|}
\hline \multirow{2}{*}{$\begin{array}{l}\text { Neutrophil level after } 7 \\
\text { days onset }\end{array}$} & \multirow{2}{*}{$\mathrm{N}$} & \multicolumn{3}{|c|}{ NIHSS score after 7 days onset $\mathrm{n}(\%)$} & \multirow{2}{*}{ Average } & \multirow{2}{*}{ SD } & \multirow[t]{2}{*}{ p value* } \\
\hline & & Mild & Moderate & severe & & & \\
\hline Normal 2.5-7.5 x103/uL & 65 & $16(24,6)$ & $17(26,1)$ & $2(3,1)$ & 6.06 & 3.1 & $0.037 * *$ \\
\hline Uppers > 7.5 x103/uL & 65 & $7(10,7)$ & $18(27,7)$ & $5(7,7)$ & 8.03 & 3.2 & \\
\hline
\end{tabular}

** significant 
Relationship results the mean NIHSS with neutrophil levels in patients with intense ischemic stroke beginning 72 hours, the mean NIHSS was $11.3 \pm 3.1$ with $r=0.328$ and was significantly related to $\mathrm{p}=0.008$ where the higher the neutrophil level, the worse the clinical outcome, whereas on day 7 On onset, the NIHSS value decreased with a mean of $7.9 \pm 3.3$ with $r=0.585$ with a significant relationship $p=<0.001$ where the higher the neutrophil level, the worse the clinical outcome (Table 4).

Table 4. Correlation of the mean NIHSS with neutrophil levels in patients with acute ischemic stroke 72 hours of onset and 7 days of onset

\begin{tabular}{llllll}
\hline Neutrophil levels & $\mathrm{n}$ & NIHSS Average & SD & $\begin{array}{l}\text { Correlation } \\
\text { coefficient }\end{array}$ & P value* \\
\hline$<72$ hours & 65 & 11.3 & 3.1 & $\mathrm{r}=0.328$ & $0.008^{* *}$ \\
7th days from onset & 65 & 7.9 & 3.3 & $\mathrm{r}=0.585$ & $<0.001^{* *}$ \\
\hline
\end{tabular}

* Spearman Correlation test

** significant

The results of the relationship with confounding variables with neutrophil levels were known to be only statistically significant in cases of pneumonia with $r=0.321$ and $p=0.009$, which means the presence of pneumonia made neutrophil levels increase, while the results of confounding factors with NIHSS differences were significant in the incidence of hypertension with $r=0.272$ where patients with hypertension, the worse the clinical outcome (Table 5).

Table 5 Correlation of confounding variables with neutrophils and differences in NIHSS scores

\begin{tabular}{lllll}
\hline Variable & \multicolumn{2}{c}{ Neutrophil levels } & \multicolumn{2}{c}{ NIHSS score difference } \\
\cline { 2 - 5 } & \multicolumn{1}{c}{ Correlation coefficient } & $\mathrm{p}$ value* & Correlation coefficient & $\mathrm{p}$ value* \\
\hline Gender & $\mathrm{r}=-0.273$ & 0.439 & $\mathrm{r}=-0.079$ & 0.532 \\
Age (years) & $\mathrm{r}=-0.218$ & 0.720 & $\mathrm{r}=-0.113$ & 0.371 \\
Hypertension & $\mathrm{r}=-0.980$ & 0.259 & $\mathrm{r}=-0.272$ & $0.028^{* *}$ \\
Dyslipidemia & $\mathrm{r}=0.220$ & 0.078 & $\mathrm{r}=0.187$ & 0.237 \\
Diabetes mellitus & $\mathrm{r}=0.122$ & 0.334 & $\mathrm{r}=0.027$ & 0.828 \\
Pneumonia & $\mathrm{r}=0.321$ & $0.009 * *$ & $\mathrm{r}=0.091$ & 0.469 \\
Urinary tract infections & $\mathrm{r}=0.127$ & 0.340 & $\mathrm{r}=-0.120$ & 0.340 \\
Decubitus & $\mathrm{r}=0.200$ & 0.110 & $\mathrm{r}=0.179$ & 0.155 \\
\hline
\end{tabular}

*Spearman Correlation test

** significant

NIHSS: National Institutes of Health Stroke Scale. 


\section{Discussion}

Research has 65 subjects of extraordinary ischemic stroke patients who were treated at Dr. Clinical center. Soetomo during the period from January to March 2021 through stroke library data. General credits of study subjects included age, sex and pace of pollution during treatment. As explained by Patricia et al, (2013) that factors that can cause stroke isolates into modifiable and non-modifiable factors. Factors that can't be modified include mature enough and sex, while factors that can be changed fuse hypertension, diabetes mellitus, lipid profile, alcohol drunk and smoking.(Patricia, Kembuan and Tumboimbela, 2015)

Hypertension is a significant danger factor for stroke. Arranged as hypertension when pulse is more noteworthy than or equivalent to $140 / 90 \mathrm{mmHg}$. In this review, 49 subjects with hypertension (75.4\%) demonstrated that hypertension was the most widely recognized danger factor for ischemic stroke. According to Mauricio's research, The main and most significant risk factor is hypertension and is found in about $82 \%$ of patients with diabetes mellitus.(Wajngarten and Sampaio Silva, 2019) This study is a longitudinal approach to look at changes in the acute ischemic stroke inflammatory reaction in the early phase with onset 0-72 hours (days 1 to 3) from onset, these data were obtained by taking anamnesis from the subject/patient or their family seriously about the date of birth. onset and time of occurrence, as well as the date and time signed when the MRS. This timeframe is based on the theory and method of research reports that the inflammatory process occurs from early or later disease onset; even neutrophils up to 2-3 days later. High neutrophil levels at onset 72 hours with mean8.62 $\pm 2.5 \times 103 / \mathrm{uL}$ and on the 7 th day of onset neutrophils were found to be $8.03 \pm 3.2$ x103/uL.

In this study, the age of the patients was $57.42 \pm 12.36$ years, the mean age of the patients was according to the epidemiological assessment with respect to the marks of stroke which said that the greatest age pack was in the 61-70 years year age group.(Damayanti, Amalia and Sudjud, 2018) One of the most grounded peril variable of ischemic stroke is age. On various words, as age constructs, the event of stroke similarly increases.(Patricia, Kembuan and Tumboimbela, 2015) At the moment that a singular turns 55 years old, the rate will twofold every decade. Sex brand name data is similarly one of the unmodifiable peril factors for stroke. This is according to a concentrate by Ahangar AA, et al. (2018) who showed that men have a 30\% more risk of having a stroke than women.(Ahangar et al., 2018) According to Patricia et al. (2013), most patients with ischemic stroke are male.(Patricia, Kembuan and Tumboimbela, 2015)

Studies on the comparison between the number of neutrophils and the clinical outcome of ischemic stroke are still varied. Wang et al observed 90 days of acute ischemic stroke and found a high neutrophil count during acute ischemic stroke was associated with poor clinical outcome.(Wang and Wang, 2019) Sulaive et all failed to prove the association of neutrophils with the clinical outcome of ischemic stroke. The ischemic cascade is composed of the roles of many inflammatory cells, and neutrophils are only one intermediate component involved.(Sulaieva et al., 2015) In this study, there was no relationship between the two variables due to the short measurement range and many influential factors in the ischemic cascade, while neutrophils were only one component in the ischemic cascade chain.

This study also did not find a significant relationship between age and changes in NIHSS scores. Some literature states that age is a risk factor for stroke and one of the factors that also affects the clinical outcome of stroke, but hypertension, in this study, is more dominant in determining the clinical outcome of ischemic stroke. Likewise, in the correlation test between sex and changes in the NIHSS score, there was no significant relationship. Male gender was proven to be a risk factor for ischemic stroke, but it was not proven to affect the 
clinical outcome of acute ischemic stroke. The results of the correlation test on all subjects did not find a significant relationship between DM and all subjects. This finding contradicts the study of Patricia. which stated that DM had an effect on the clinical outcome of ischemic stroke.(Patricia, Kembuan and Tumboimbela, 2015) Tun said that patients with acute ischemic stroke with DM had a worse clinical outcome and tended to have a more severe degree of stroke. The proportion of subjects with DM which is less in this study causes the correlation test to have no significant relationship.(Tun Nyo Nyo et al., 2017)

The study of Tziomalos et al said that in patients with acute ischemic stroke, lipid profile disorders caused poor clinical outcomes for sufferers.(Tziomalos et al., 2009) Pol said that lipid profile disorders will cause ischemic stroke sufferers to experience cardiovascular complications that cause poor clinical outcomes for sufferers.(Pol et al., 2018) In this study, the number of patients with dyslipidemia was 35 (53.8\%) and all subjects had normoweight nutritional status, so there was no significant relationship between dyslipidemia and changes in NIHSS scores.

According to research from Bianca of 15 patients studied there were 9 patients with high neutrophils found within 24 hours of onset. This is according to the theory that in the serious stage aggravation occurs as leukocyte advancement which is affected by TNF-and IL-1 cytokines, especially neutrophils that go to ischemic areas.(Bianca et al., 2013) After the extraordinary period has passed, the provocative reaction ceaselessly disappears put aside by a reducing in the levels of proinflammatory cytokines created. The mean NIHSS score on the seventh day of treatment was lower and the verifiable exploratory results showed that there was an enormous differentiation between the NIHSS score of starting 72 hours and the seventh day of treatment, $\mathrm{p}<0.05$. Changes in the NIHSS score can depict changes in the level of seriousness of ischemic stroke endured by the patient. This is like William's review which reasoned that neutrophils in intense ischemic stroke patients with high NIHSS scores at emergency clinic confirmation were related with poor practical outcome.(William Prasetiyo, Husni and Tugasworo, 2017) The decline in the NIHSS score is believed to be identified with the job of physiotherapy given additionally to the capacity of the mind to defeat reperfusion injury, where free extremists assume a part all the while. Examination of neutrophil levels and NIHSS scores in patients with intense ischemic stroke beginning 72 hours and on day 7 of beginning, a $p$ worth of 0.001 was gotten. The connection between neutrophils in intense ischemic stroke patients and clinical results utilizing the NIHSS score was critical, which was huge through the Spearman relationship test with $\mathrm{p}$ esteem $=0.008$, so it very well may be presumed that underlying neutrophil levels could be utilized to anticipate the NIHSS score acquired. Kömürcü in his examination said that high leukocyte and neutrophil counts were related with vascular infection and could be an indicator of stroke severity.(Kömürcü et al., 2020)

These outcomes are steady with the pathophysiology of intense cell ischemic stroke when tissue ischemia happens, neutrophils will stick to and move across the endothelium of the mind microvasculature. At the time in the extravascular neutrophils will deliver free revolutionaries, discharge proteolytic proteins, invigorate the arrival of neutrophils that cause the development of neutrophils and different leukocytes. Large quantities of neutrophils during reperfusion, intravascular neutrophils and tissue aggregation are parts of the fiery reaction.(Pedersen et al., 1997; Pandian et al., 2014).

Neutrophils can cause worsening of the outcome through obstruction of the microcirculation and vasoconstriction and infiltration of neurons. In ischemic conditions there is an increase in the production of free radicals during reperfusion. The imbalance between the production of free radicals can affect cerebral function and damage neuronal cells through the mechanism of increased lipid peroxidase in cell membranes, oxidative DNA damage, protein damage and induction of apoptosis and necrosis. The strength of this research 
is the longitudinal observation research method which gives the accuracy of the results obtained. Meanwhile, the weakness of this study was that it did not calculate neutrophil levels with the extent of infarction on a CT scan of the head and did not measure neutrophil levels serially

\section{Conclusions}

There is a significant difference between changes in neutrophil levels and clinical outcome in patients with acute ischemic stroke $<72$ hours and the onset of day 7, that the higher the neutrophil level, the worse the clinical outcome of stroke with $\mathrm{p}$ significant $<0,05$. Further research is needed on the relationship between neutrophil levels and the size of the lesion.

Author Contributions: Conceptualization, A.F, M.S.A and M.B.; methodology, M.S.A and M.B; software, A.F; validation, A.F., M.S.A and M.B.; formal analysis, A.F; investigation, A.F. and M.S.A.; resources, M.S.A. and M.B.; data curation, M.B.; writing — original draft preparation, A.F; writing — review and editing, A.F, M.S.A and M.B.; visualization, A.F; supervision, M.S.A. and M.B.; project administration, A.F.; funding acquisition, A.F., M.S.A and M.B.. All authors have read and agreed to the published version of the manuscript.

Funding: This research received no external funding.

Institutional Review Board Statement: Ethical clearance was not applicable for this study.

Informed Consent Statement: Informed consent was obtained from all subjects involved in the study.

Data Availability Statement: Data sharing not applicable

Acknowledgments: none

Conflicts of Interest: The authors declare no conflict of interest.

\section{References}

Ahangar, A. A. et al. (2018) 'Sex difference in types and distribution of risk factors in ischemic and hemorrhagic stroke', International Journal of Stroke, 13(1), pp. 83-86. doi: 10.1177/1747493017724626.

Audebert, H. J. et al. (2004) 'Systemic inflammatory response depends on initial stroke severity but is attenuated by successful thrombolysis', Stroke, 35(9), pp. 2128-2133. doi: 10.1161/01.STR.0000137607.61697.77.

Bianca, L. et al. (2013) 'Hubungan Kadar Neutrofil Dengan Luaran Klinis Penderita Stroke Iskemik Akut'.

Buck, B. H. et al. (2008) 'Early neutrophilia is associated with volume of ischemic tissue in acute stroke', Stroke, 39(2), pp. 355-360. doi: 10.1161/STROKEAHA.107.490128.

Campbell, B. C. V. and Khatri, P. (2020) 'Stroke', The Lancet, 396(10244), pp. 129-142. doi: 10.1016/S0140-6736(20)31179-X.

Damayanti, A., Amalia, L. and Sudjud, R. W. (2018) 'Characteristics of Cardioembolic Stroke Patient in Neurologic Ward Dr. Hasan Sadikin General Hospital Bandung', Journal of Medicine \& Health, 2(1). doi: 10.28932/jmh.v2i1.740.

Eichmann, A. and Thomas, J. L. (2013) 'Molecular parallels between neural and vascular development', Cold Spring Harbor Perspectives in Medicine. doi: 10.1101/cshperspect.a006551.

Jickling, G. C. et al. (2015) 'Targeting neutrophils in ischemic stroke: Translational insights from experimental studies', Journal of Cerebral Blood Flow and Metabolism, 35(6), pp. 888-901. doi: 10.1038/jcbfm.2015.45.

Kömürcü, H. F. et al. (2020) 'Changes in neutrophil, lymphocyte, platelet ratios and their relationship with NIHSS after rtPA and/or thrombectomy in ischemic stroke', Journal of Stroke and Cerebrovascular Diseases, 29(8). doi: $10.1016 /$ j.jstrokecerebrovasdis.2020.105004.

Lyden, P. (2017) 'Using the National Institutes of Health Stroke Scale', Stroke, pp. 513-519. doi: 10.1161/STROKEAHA.116.015434.

Meloni, B. P. (2017) 'Pathophysiology and neuroprotective strategies in hypoxic-ischemic brain injury and stroke', Brain Sciences, 7(8), pp. 11-14. doi: 10.3390/brainsci7080110.

Pandian, J. D. et al. (2014) 'Mirror therapy in unilateral neglect after stroke (MUST trial): A randomized controlled trial', Neurology, 83(11), pp. 1012-1017. doi: 10.1212/WNL.0000000000000773.

Patricia, H., Kembuan, M. A. H. N. and Tumboimbela, M. J. (2015) 'KARAKTERISTIK PENDERITA STROKE ISKEMIK YANG DI RAWAT INAP DI RSUP PROF. DR. R. D. KANDOU MANADO TAHUN 2012-2013', e-CliniC, 3(1). doi: 10.35790/ecl.3.1.2015.7402. 
Pedersen, P. M. et al. (1997) 'Hemineglect in acute stroke - Incidence and prognostic implications: The Copenhagen Stroke Study', American Journal of Physical Medicine and Rehabilitation, 76(2), pp. 122-127. doi: 10.1097/00002060-199703000-00007.

Pol, T. et al. (2018) 'Dyslipidemia and risk of cardiovascular events in patients with atrial fibrillation treated with oral anticoagulation therapy: Insights from the ARISTOTLE (Apixaban for Reduction in Stroke and Other Thromboembolic Events in Atrial Fibrillation) trial', Journal of the American Heart Association, 7(3), pp. 1-11. doi: 10.1161/JAHA.117.007444.

Ropper, A. et al. (2019) Adams and Victor's Principles of Neurology Eleventh Edition. Eleventh E, Journal of Chemical Information and Modeling. Eleventh E. McGraw-Hill Education.

Sacco, R. L. et al. (2013) 'An updated definition of stroke for the 21st century: A statement for healthcare professionals from the American heart association/American stroke association', Stroke, 44(7), pp. 2064-2089. doi: 10.1161/STR.0b013e318296aeca.

Sulaieva, O. N. et al. (2015) 'Leukocytes dysfunction predicts outcome in patients with ischemic stroke Introduction As it is commonly recognized the most often cause of a stroke is the sudden occlusion of', (June).

Tun Nyo Nyo et al. (2017) 'Diabetes mellitus and stroke: A clinical update', World Journal of Diabetes, 8(6), pp. $235-248$.

Tziomalos, K. et al. (2009) 'Dyslipidemia as a Risk Factor for Ischemic Stroke', Current Topics in Medicinal Chemistry, 9(14), pp. 1291-1297. doi: 10.2174/156802609789869628.

Venketasubramanian, N. et al. (2017) 'Stroke Epidemiology in South, East , and South-East Asia : A Review', 19(3), pp. $286-294$.

Wajngarten, M. and Sampaio Silva, G. (2019) 'Hypertension and stroke: Update on treatment', European Cardiology Review , 14(2), pp. 111-115. doi: 10.15420/ecr.2019.11.1.

Walsh, S. R. et al. (2005) 'Neutrophil-Lymphocyte Ratio as a Prognostic Factor in Colorectal Cancer', (June), pp. 181-184. doi: $10.1002 /$ jso.20329.

Wang, W. Y. et al. (2015) 'Role of pro-inflammatory cytokines released from microglia in Alzheimer's disease', Annals of Translational Medicine, 3(10), pp. 1-15. doi: 10.3978/j.issn.2305-5839.2015.03.49.

Wang, Yilong and Wang, Yongjun (2019) 'Platelet Count Predicts Adverse Clinical Outcomes After Ischemic Stroke or TIA : Subgroup Analysis of', 10(April), pp. 1-7. doi: 10.3389/fneur.2019.00370.

William Prasetiyo, Y., Husni, A. and Tugasworo, D. (2017) 'Correlation Among Neutrophil Count and Serum Hs-Crp Levels With Clinical Outcome of Acute Infarction Stroke Patients', 34(3).

$\mathrm{Xu}$, J. et al. (2019) 'Higher Platelet-to-Lymphocyte Ratio Is Associated With Worse Outcomes After Intravenous Thrombolysis in Acute Ischaemic Stroke', 10(November), pp. 1-8. doi: 10.3389/fneur.2019.01192. 